\title{
Dehospitalization of technology-dependent children: the perspective of the multiprofessional health team
}

\author{
Desospitalização de crianças dependentes de tecnologias: \\ perspectiva da equipe multiprofissional de saúde \\ Deshospitalización de niños que dependen de tecnologías: \\ la perspectiva del equipo multiprofesional de salud
}

\section{Kassiely Klein ${ }^{a}$ Helena Becker Issi ${ }^{b}$ Neila Santini de Souzac Aline Cammarano Ribeiro ${ }^{\mathrm{d}, \mathrm{e}}$ Érika Eberlline Pacheco dos Santos ${ }^{\mathrm{e}}$ Graciela Dutra Senhem ${ }^{\mathrm{d}, \mathrm{e}}$}

\section{How to cite this article:} Klein K, Issi HB, Souza NS, Ribeiro AC, Santos EEP, Senhem GD. Dehospitalization of technology-dependent children: the perspective of the multiprofessional health team. Rev Gaúcha Enferm. 2021;42:e20200305. doi: https://doi. org/10.1590/1983-1447.2021.20200305 a Universidade Federal do Rio Grande do Su (UFRGS). Escola de Enfermagem, Programa de PósGraduação em Saúde da Criança e do Adolescente. Porto Alegre, Rio Grande do Sul, Brasil.

${ }^{6}$ Universidade Federal do Rio Grande do Sul (UFRGS), Escola de Enfermagem, Departamento de Enfermagem Materno-Infantil. Porto Alegre, Rio Grande do Sul, Brasil.

Universidade Federal de Santa Maria (UFSM). Departamento de Ciências da Saúde. Palmeira das Missões, Rio Grande do Sul, Brasil.

d Universidade Federal de Santa Maria (UFSM). Centro de Ciências da Saúde, Departamento de Enfermagem, Santa Maria, Rio Grande do Sul, Brasil.

' Universidade Federal de Santa Maria (UFSM) Programa de Pós-graduação em Enfermagem. Santa Maria, Rio Grande do Sul, Brasil.

\section{ABSTRACT}

Objective: To know the dehospitalization of technology-dependent children from a multiprofessional perspective.

Method: A qualitative, exploratory and descriptive study, carried out in 2018 at a Teaching Hospital in the city of Porto Alegre. The participants were 15 members of the multidisciplinary health team. In data production, we used the Dynamics of Creativity and Sensitivity, "Creative Storm", which is part of the Sensitive Creative Method. Data interpretation occurred based on Thematic Content Analysis. The study was approved by the Ethics Committee.

Results: Dehospitalization is influenced by the absence of planning according to the reality of the child and the family. In addition, there is predominance of health services with a physician-centered model, unscheduled discharge, overload of professionals, and communication problems between the staff, the health network and the family.

Final Considerations: Despite knowing the importance of dehospitalization, it still occurs in a fragmented manner, with hasty hospital discharge, preventing safe dehospitalization and with greater planning.

Keywords: Child. Chronic disease. Patient discharge. Patient care team. Comprehensive health care

\section{RESUMO}

Objetivo: Conhecer a desospitalização de crianças dependentes de tecnologias na perspectiva multiprofissional de saúde

Método: Estudo qualitativo, exploratório descritivo, realizado em um hospital-escola no Município de Porto Alegre, em 2018. Participaram 15 integrantes da equipe multiprofissional de saúde. Na produção dos dados, utilizou-se a Dinâmica de Criatividade e Sensibilidade "Tempestade Criativa", do Método Criativo Sensível. A interpretação dos dados ocorreu a partir da Análise de Conteúdo Temática. 0 estudo foi aprovado pelo Comitê de Ética.

Resultados: A desospitalização pode ser influenciada pela ausência de um planejamento de acordo com a realidade da criança e família. Além disso, tem-se o predomínio dos serviços de saúde com modelo centrado no médico, com altas não programadas, sobrecarga dos profissionais e problemas na comunicação entre equipe, rede de saúde e família.

Considerações finais: Apesar de saber-se da importância da desospitalização, ela ocorre de forma fragmentada, com altas hospitalares precipitadas, impedindo uma desospitalização segura e com maior planejamento.

Palavras-chave: Criança. Doença crônica. Alta do paciente. Equipe de assistência ao paciente. Assistência integral à saúde.

\section{RESUMEN}

Objetivo: conocer la deshospitalización de niños que dependen de la tecnología desde una perspectiva multiprofesional de salud. Método: Estudio cualitativo, exploratorio y descriptivo, realizado en 2018 en un Hospital Escuela de la ciudad de Porto Alegre. Participaron 15 integrantes del equipo multiprofesional. En la recopilación de datos, se utilizó la Dinámica de la Creatividad y la Sensibilidad, "Tormenta creativa”, que forma parte del Método Creativo Sensible. La interpretación de los datos se produjo a partir del Análisis de Contenido Temático. El estudio fue aprobado por el Comité de Ética.

Resultados: Una deshospitalización inadecuada está influida por la ausencia de planificación acorde a la realidad del niño y de la familia. Además, hay predominio de servicios de salud con un modelo centrado en los médicos, con altas no programadas, sobrecarga de profesionales y problemas en la comunicación entre personal, red de salud y familia.

Consideraciones finales: A pesar de conocer la importancia de la deshospitalización, aún se da en forma fragmentada, con altas hospitalarias precipitadas, lo que impide una deshospitalización segura y con mayor planificación.

Palabras clave: Niño. Enfermedad crónica. Alta del paciente. Grupo de atención al paciente. Atención integral de la salud. 


\section{口INTRODUCTION}

With the advancements of the health technologies in Pediatrics, a significant reduction in childhood mortality and an increase in the survival of clinically-weakened children are observed. Thus, there was a growing number of children with chronic diseases, who often need special care to maintain their health. This particular group can be classified as Children with Special Health Needs (Crianças com Necessidades Especiais de Saúde, (RIANES)(1).

This research was conducted according to the theoretical framework of CRIANES, who are children that are at physical, developmental or behavioral risk or with an increased emotional condition, and who need a type of health care and services beyond what is required by children in general. This care requires expanded knowledge from health professionals and family members; however, they do not always have the necessary knowledge and are often not adequately qualified to provide care to these children ${ }^{(2)}$.

Between 2011 and 2012, in the USA it was identified that $19.8 \%$ of the children and adolescents aged from 0 to 17 years old presented special health needs. In Brazil, this group is invisibilized in the official statistics.

In a research study to validate the Children with Special Health Care Needs Screener instrument for Brazil, the participants were 140 family members of children aged from 0 to 12 years old attending the outpatient clinic and emergency service of a teaching hospital in the South of the country. This instrument assesses the care demands of each child according to three domains: dependence on medications, use of the health services considered more complex than routine services, and presence of functional limitations. Through it, it was observed that the prevalence of children with special health needs was $36 \%$. Among them, $28 \%$ presented dependence on medications, $24 \%$ needed to continuously resort to the health services, and $6 \%$ presented functional limitations ${ }^{(3)}$.

Among the CRIANES, there are technology-dependent children (TDC) who need to use medical devices as a result of a situation or health problem, in order to compensate for the loss of a certain vital function of the organism. This type of patients needs special daily care to preserve their health and avoid further complications ${ }^{(3)}$. A number of research show that TDC present the following as main technological care options: ventriculoperitoneal shunt, gastrostomy, oxygen therapy, tracheostomy and nasoenteral tube ${ }^{(4-6)}$. Considering TDC, the use of technologies determines their survival and enables, in certain cases, dehospitalization as an opportunity to be at their homes and following the treatment. This situation demands special and continuing care that fall under the responsibility of a family member/caregiver. Therefore, dehospitalization also presents itself as a way of providing better quality of life to the child(7).

The challenges of TDC dehospitalization not only focus on the multidisciplinary health team, but also on the family members/caregivers, as they need to adapt to a new care routine, reorganizing the family structure, learning to manipulate medical devices, and readjusting roles for the implementation of home care ${ }^{(8)}$.

This population of TDC poses numerous challenges related to safe dehospitalization to the health professionals. Therefore, the intervention of a multidisciplinary health team becomes necessary, in addition to a planned hospital discharge, which takes into account several aspects, such as: the family's wish to take the child home; the preparation and training of the family members/caregivers; the child's clinical condition; legal referrals and access to benefits and aids; access to the materials and equipment that this child will need, as well as structuring of the health care network that this family will access after hospital discharge ${ }^{(7-9)}$.

In addition to the family network, the child and family members/caregivers can count on the help of the government program called Home Care (Atenção Domiciliar, AD), established by Ministry of Health Ordinance No. 825 of April $25^{\text {th }}, 2016$, which redefines AD within the scope of the Unified Health System (Sistema Único de Saúde, SUS). This network is made available in three modalities: AD1, AD2 and AD3.

In AD1, the users are assisted by the Primary Health Care (PHC) teams. TDC can use the AD2 and AD3 modalities, which receive care from the Home Care Service (Serviço de Atenção Domiciliar, SAD), in which assistance is guided by the user's home care needs $s^{(10-11)}$.

Given the above, the need for the involvement of a multidisciplinary team based on interprofessional health care is considered, which enables the construction of knowledge and provides the necessary conditions for resoluteness in the health care provided to the TDC. Interdisciplinary knowledge and interprofessional work have greater potential in collaborative health practices and seek to solve the problems that afflict children and families. Interdisciplinarity offers a biopsychosocial perspective and becomes a fundamental practice to strengthen the integrity of the Unified Health System ${ }^{(8)}$.

A number of research studies show that the dehospitalization of CRIANES occurs without care continuity, resulting from a weakened network ${ }^{(6-12)}$, in which there is redefinition of feelings and care when the children return to their homes. Consequently, the professionals need to readapt to the work process, which evidences a gap to be explored in the production of knowledge on dehospitalization ${ }^{(6,12-13)}$.

Therefore, the following research question emerges: How does the dehospitalization of technology-dependent children occur from the perspective of the multiprofessional 
health team? The objective of this study is to learn about the dehospitalization of technology-dependent children from the perspective of the multiprofessional health team.

\section{$\square$ METHOD}

This is a qualitative study, of the descriptive and exploratory type. The Dynamics of Creativity and Sensitivity (DCS) of the Sensitive Creative Method (SCM) were used to develop the research. The dynamics of creativity and sensitivity combine consolidated techniques in data production, collective interview, group discussion and participant observation to produce data in the group space in a dynamic and dialogic manner ${ }^{(14)}$. The research was carried out in 2018 in a teaching hospital of the Municipality of Porto Alegre, state of Rio Grande do Sul, Brazil. Data collection was conducted with nurses, physicians, nutritionists, physiotherapists, social workers, physical educators, speech therapists, psychologists and pharmacists working in the Pediatric Hospitalization Unit.

This Pediatric Hospitalization Unit admits children aged from two days to six years old, as it is the reference unit for neonates and children after discharge from the neonatal and pediatric intensive care unit who still need hospitalization, training for home discharge, or for those waiting some court appeal to receive the child at their home. These children are sometimes dependent on technologies such as tracheostomy, oxygen therapy, mechanical ventilation, enteral and gastric feeding tubes, central venous catheters, and other devices to maintain life and its quality.

In 2019, 747 children were admitted to the pediatric hospitalization unit; of these, it is estimated that $80 \%$ are CRIANES, as the hospital is a reference for complex health care. The group of TDC is included in this percentage, demanding constant care from the assistance team to organize safe dehospitalization.

The research inclusion criteria were as follows: being a health professional working in this pediatric hospitalization unit and having experienced at least once the TDC dehospitalization process. The exclusion criterion was the following: professionals unable to perform their duties due to work leaves. There was no exclusion given the criterion established.

The professionals of the multiprofessional health team were previously approached in the service and invited to participate in the research. After acceptance, they received via email the date, time and location of the DCS, which was held in a room provided by the hospital guaranteeing the participants' privacy. At the group meeting, the Free and Informed Consent Form was handed in for them to read it and sign it.

It is noteworthy that the DCS mediator was the main researcher, who had previous experience in group data production using the dynamics of creativity and sensitivity, and the research assistant had been previously trained along with the research group to which the study is linked.

To conduct the DCS, five stages were recommended. Stage 1 - Welcoming (nearly five minutes): it consisted of the participants, group mediator and research assistant introductions, with the presentation of the theme proposed for the meeting and explanation of the objective of the group dynamics for the production of the research data, which was to know the perceptions of the multidisciplinary health team about the dehospitalization of technology-dependent children. In Stage 2 - Individual or collective work (nearly fifteen minutes), the individual artistic productions were carried out, through the DCS called Creative Storm ${ }^{(14)}$, using the metaphor of storm elements such as rain, sun, lightning, cloud, and wind; each of these elements was delivered to the participants in a drawing format. To develop the activity, the group mediator launched the following debate question (DQ): How do you see the dehospitalization of technology-dependent children? In Stage 3 - Presentation of the artistic productions (nearly ten minutes): there was verbal presentation and exposition of the individual productions in the group space. At that moment, each participant expressed their perspective through the Creative Storm elements, awakening the creative and sensitive dimension, which was latent from their experiences in the dehospitalization of TDC. During this stage, the group mediator and the research assistant recorded the subject matters, from which the generating themes were coded, taking note of the keywords. Stage 4 - Collective analysis and group discussion (nearly thirty minutes): it was the moment devoted to decoding the generating subthemes. In Stage 5 - Thematic synthesis and data validation (nearly five minutes): the meeting was closed, based on the synthesis of the generating themes produced in the group space, with validation of the data produced in the group.

The research participants were 15 health professionals from different training areas, who were divided in two different groups. According to what the method recommends, smaller groups enable data production with greater ease for transcription. A single DQ was addressed: How do you see the dehospitalization of technology-dependent children?

During the meetings, a digital recorder was used to record the group discussions and, later, these were transcribed by the main researcher. The photographic records of the artistic productions served to illustrate the DCS participants'statements in the data production stage. Two meeting lasting approximately sixty minutes were held. A research assistant, who collaborated in the audio recordings and in the field diary, and a mediator, who acted as group intermediation for the DCS, also participated in the meeting. To conduct the DCS, materials such as colored cardboard, pen, marker, scissors, brown paper and glue were used. 
For the criterion to finish the field work, theoretical saturation was used, in which the researcher verifies that no new facts arise and that all the concepts have been developed $^{(15)}$. Data analysis was performed by means of Thematic Content Analysis, which is subdivided into three stages: reading the selected material ( $1^{\text {st }}$ stage); exploration of the material ( $2^{\text {nd }}$ stage); and elaboration of an interpretive synthesis ( $3^{\text {rd }}$ stage $)^{(16)}$.

The project was submitted for appreciation of the Research Ethics Committee of the institution involved, being approved under Opinion No.2,614,102/2018, and through Plataforma Brasil, where it is found with CAAE No:: 84912218.0.0000.5327. The research developed is based on the bioethical precepts set forth in Resolution 466/2012. In order to preserve their anonymity, the participants were identified with the letter "P", followed by numerals according to the participation sequence in the research, such as P1, P2, and so on.

\section{RESULTS}

The 15 participating health professionals were two physicians, two physical educators, two social workers, two pharmacists, two physiotherapists, two nutritionists, one speech therapist, one nurse, and one psychologist. They had a mean of 9.93 years since graduation and 5.26 years of experience in the service. As for their training degrees, five had a master's degree and ten had some specialization.

The study results are presented below based on the following categories: "The challenges faced by the multiprofessional team regarding the dehospitalization of technology-dependent children" and "The potentialities for the safe dehospitalization of technology-dependent children".

\section{The challenges faced by the multiprofessional team regarding the dehospitalization of technology-dependent children}

Dehospitalization generates ambiguous perceptions and feelings in the team, as there are several intra- and extra-hospital weaknesses to be faced, many of them related to the deficient health system and to the precarious living conditions of the TDC, which raises concerns in the professionals. Through the artistic production called "A raindrop", it was possible to perceive that what was provided for these TDC is insufficient in view of the needs they present. These perceptions are reasserted in Figure 1 and in the participants'speeches below:

I'm upset about them not having access to everything they need, so it's a little related to the deficit of our health system, to the lack of conditions to offer them everything they need to have some comfort and a little dignity. I get a little anxious about discharging these patients. (P9)

Thinking a little about the issues of social weaknesses, we end up not being able to cope; there are many children who can't be properly prepared, because they don't have minimal living conditions! As soon as they go home, unfortunately, they won' thave anything to eat, so, forme, from a discharge perspective, these arevery serious problems. (P15)

In addition to that, planning the hospital discharge of TDC requires a series of care measures, as it must be designed for the extra-hospital reality of the family nucleus and demands from the working professionals a sensitive and expanded perspective so that the conducts are built together with the family, encouraging autonomy for care.

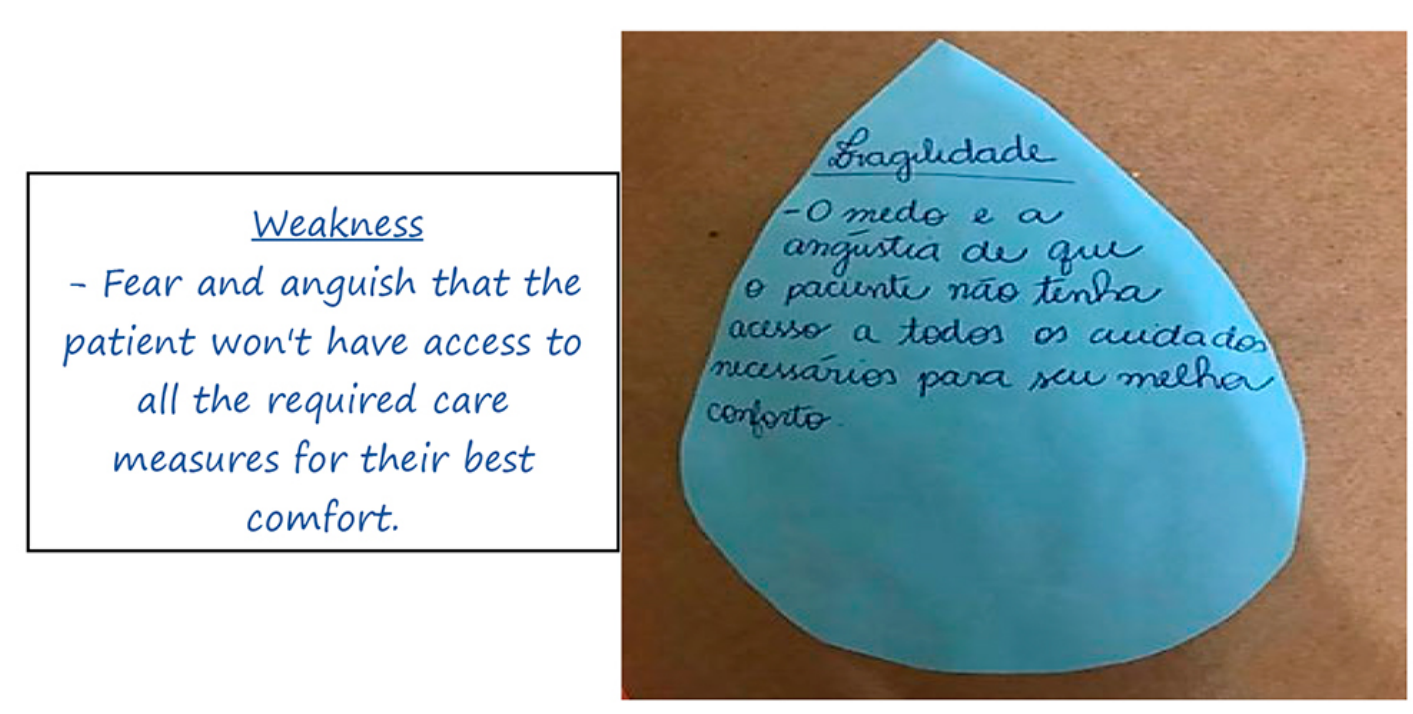

Figure 1 - Artistic production by P9 Source: Creative Storm Dynamics, 2018. 
It is necessary to understand what this child's reality is like and try not to do anything too fancy or, from our point of view, always think about the context in which they are inserted, and how their reality will be after discharge, how this process is for them and for the family during dehospitalization. (P3)

Lack of planning for hospital discharge is a weakness that hinders the dehospitalization process, as the family may not consider itself prepared to meet the TDC's needs at home. The participants reiterated that hasty discharges make it impossible for the multidisciplinary team to provide complete guidelines, precluding contact, prior planning with the health care network and the construction of a support network together with the family.

Unplanned discharge is the weak spot, when we are not able to make the referrals we need and not able to prepare the families to go home. (P10)

Unplanned hospital discharge often occurs due to the great need for bed turnover in view of the overcrowding of services, with no time to provide guidelines.

We need time (to provide guidelines) that sometimes we don't have, because other patients need to be hospitalized, because the emergency room is full, because of the room (operating room), the RR (recovery room), because of the PICU (pediatric intensive care unit). (P8)

Another weakness listed was the model centered on the physician and the cure, which weakens the conducts among the multidisciplinary team. In this model, discharge is usually carried out without the consent of all the team members, negatively influencing the dehospitalization of TDC. This is reflected through the artistic production metaphorically represented by the lightning bolt, showing a rupture among the professionals, and represented in Figure 2.

If there is a physician-centered, hospital-centric health model, we still work despite the interfaces, in a fragmented, often uni-professional way, we still have assistance with a curative focus, in short, all of this undoubtedly influences this dehospitalization issue. (P4)

There must be agreement among all the professionals in the team, I believe that everyone has to say: "Yes, this child is ready to leave, this family is prepared to stay with them at home", and that doesn't happen often. (P13)

Communication in the dehospitalization process, both among the team members and with TDC and their family, is described as fragile, sometimes scarce and ineffective. However, it is emphasized as the main instrument for the good organization and efficacy of dehospitalization. Metaphorically represented in the dynamics through the artistic production of a cloud, it blurs the care provided and the referral processes, both intra-hospital and to the health care network, directly affecting the safety of the TDC. Represented in Figure 3.

Communication among team members is a great weakness. There's lack of communication with the child and family members, difficulty in communicating with the network both from inside and outside the institution. (P8) In the multidisciplinary team weakness, I wrote: lack of communication; miscommunication; misinterpretation

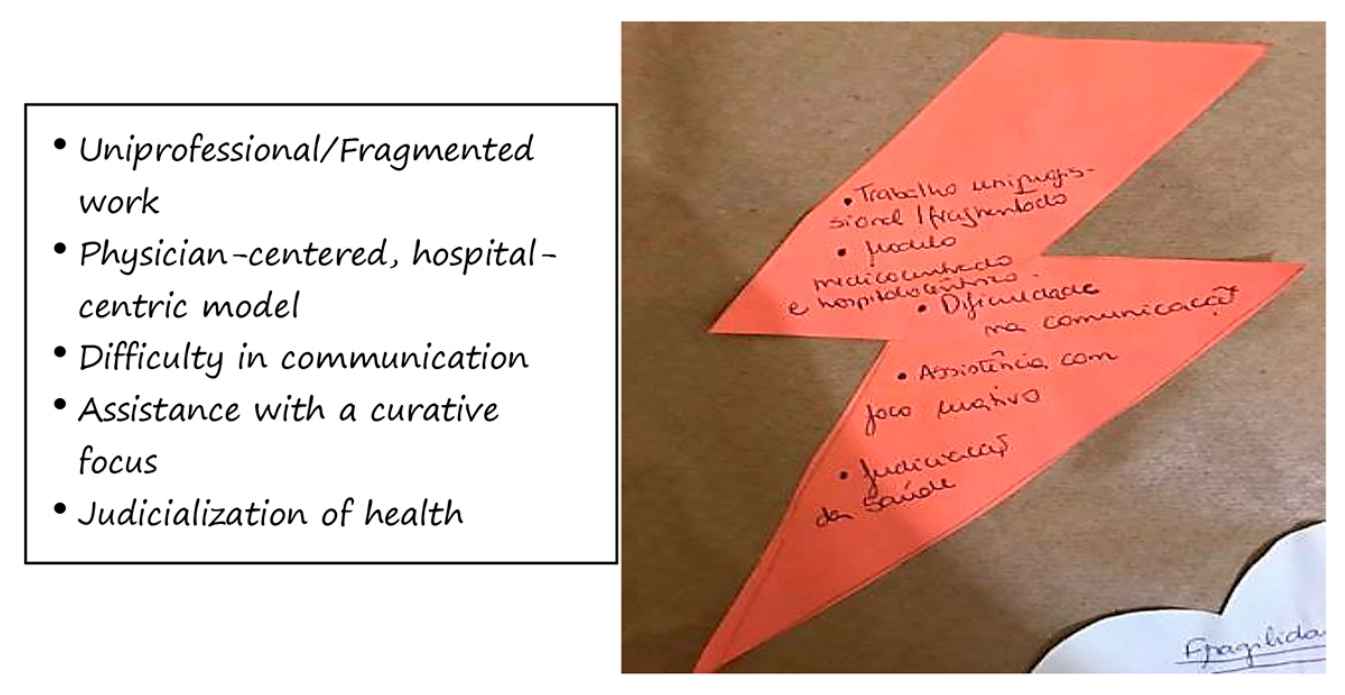

Figure $\mathbf{2}$ - Artistic production by P8 Source: Creative Storm Dynamics, 2018. 
problems, because one thing is said and another is interpreted, both among professionals, and between professionals, children and the family. (P10)

Thus, the challenges reflect the problems reported by the professionals during the TDC dehospitalization process, precluding qualified care. These are represented by the team's lack of planning for dehospitalization, hindering the strengthening of care, which needs to occur continuously. There is also bed turnover, often reducing the time to prepare the family member for care in safe dehospitalization. In addition to that, the physician-centered model and ineffective communication also undermine comprehensiveness and humanization.

\section{The potentialities for the safe dehospitalization technology-dependent children}

To carry out dehospitalization in a safe and effective manner, it is necessary that the multiple knowledge and collaborative practices at work are present in the team. Thus, interdisciplinarity is signaled as important for the care of the TDC and their family. The sun, metaphorically presented in Figure 4, represents the act of dehospitalization, offers light to the family, the rescue of life, the return to everyday life.

An engaged multiprofessional team and that the entire team is involved, that everyone knows what the colleague

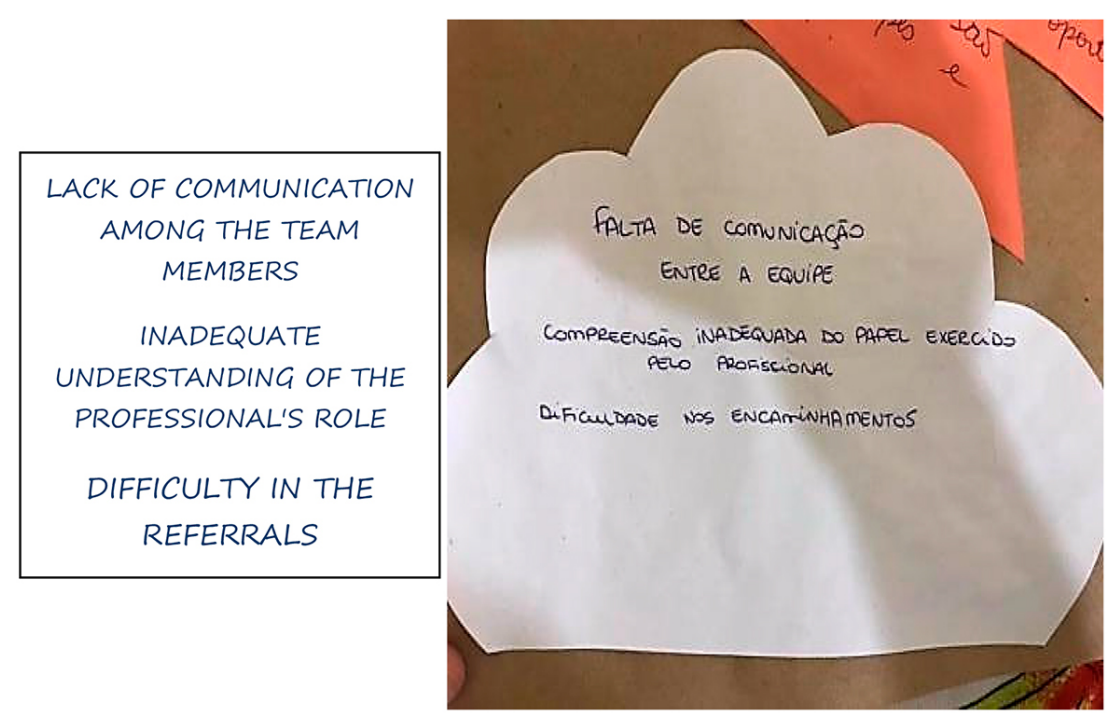

Figure $\mathbf{3}$ - Artistic production by P10

Source: Creative Storm Dynamics, 2018.

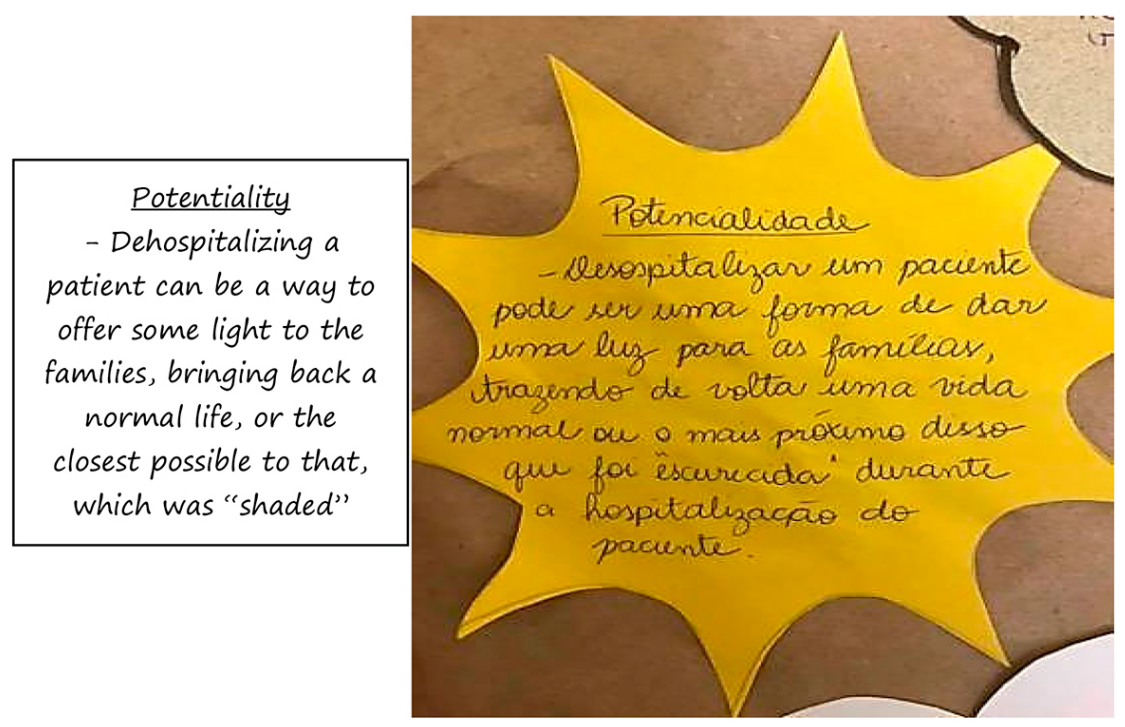

Figure 4 - Artistic production by P3

Source: Creative Storm Dynamics, 2018. 
is doing. The interdisciplinarity issue, which I think is very important, we're always thinking about the good of the patient and working together. (P3)

I think that, in the first place, the multiprofessional team being able to work with everyone engaged in the same path, knowing what the colleagues are doing, counting on them, if they have a prediction for hospital discharge, so that we know what referral they plan on doing. (P2)

The implementation of institutional protocols to improve dehospitalization was a topic widely discussed by the participants, seen as a positive strategy, capable of helping to organize the flow of this practice. The creation of these organizational mechanisms is justified in order to recognize the needs of the TDC undergoing dehospitalization, doing so in an orderly and safe manner.

Protocols have to be created, oncel read a phrase: "Protocols are not rails, they are trails." Because I have a direction to follow, the protocols make the processes safer for the patient and for the professional, [...] I think that each patient is unique, $[. .$.$] there must be individualized things,$ but the checklist and the protocol make this (dehospitalization) safer. (P1)

It is indispensable that we can have a cohesive team that works together towards the same objectives, that has flexibility and sensitivity to see the individual aspects, and that it is indeed possible to follow strict and technical protocols, but knowing that each child will have its needs and potentialities. (P14)

The word "trails" used by the professional refers to the need for a tool to direct care that provides safety for professionals and families alike in dehospitalization, considering the subjectivity of the context of each TDC. It is mentioned that this tool should be used to unify the work among the team members. When the participant says "rails", it refers to the need for this tool not to make care inflexible, but to guide its humanization and comprehensiveness.

The professionals also spoke about the importance of inserting the family in the dehospitalization process, which offers great potential, if worked on from the beginning of hospitalization, designing home care and providing more safety to the families and professionals at the time of hospital discharge.

The disease is still very much related to sin, I must've done something very wrong, "Why did it happen in my family?" It's just that. And at the same time you see these families discovering their potential, sometimes you wonder how they're going to take this child home, and they take them and assume the responsibility. So, while it's a negative thing, it sometimes brings this family together. (P4)

Therefore, the family needs to make adjustments for the safe and effective dehospitalization of the TDC, as they prepare to provide continuous home care for the child to satisfy all their needs. Artistic production 5, metaphorically represented by the sun, reveals the possibility of returning home, even though the necessary adjustments that need to be made for this to occur are inherent. Represented in Figure 5.

Now we have resources, technological equipment, so that there's this possibility of returning home and there are adjustments that this family has to make to take this child home. (P4)

The potentialities are elements that would illuminate safe dehospitalization. They are possibilities listed by the

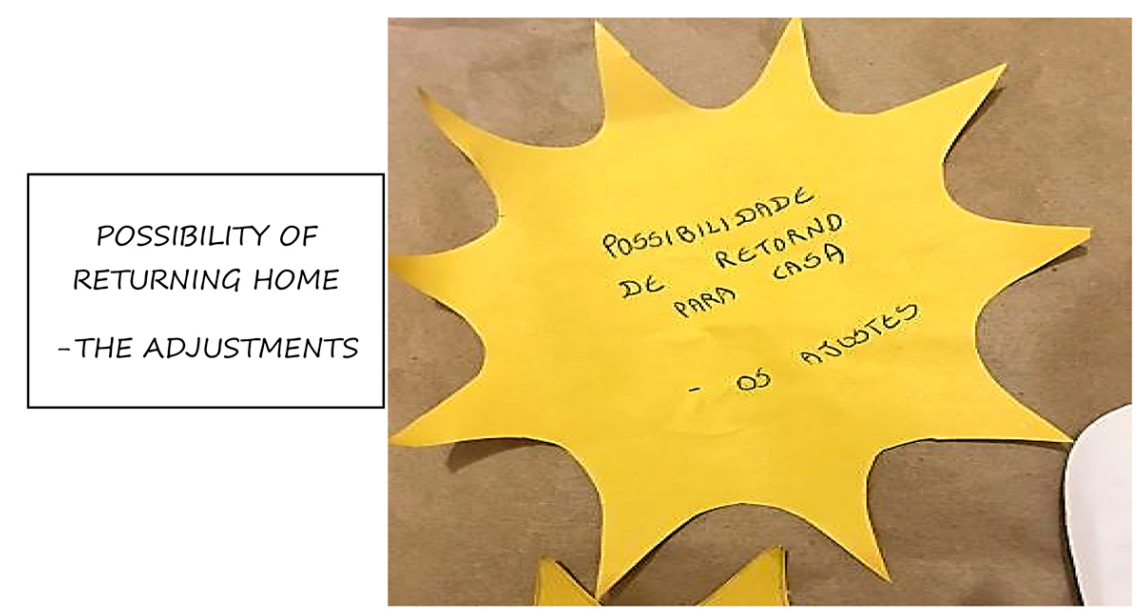

Figure $\mathbf{5}$ - Artistic production by P2

Source: Creative Storm Dynamics, 2018. 
professionals to improve this moment, represented by the inclusion of the family during all the hospitalization stages. Other elements are the implementation of effective interprofessional work and collaborative practices in health, the creation of protocols with the objective of developing linear and complete work, added to the strengthening of the support networks for safe dehospitalization.

\section{DISCUSSION}

Dehospitalization of TDC exposes them more to social vulnerability due to their health condition, which requires complex and continuous care, being directly related to the scarcity of public policies aimed at this population. The social issue is a determining factor in dehospitalization and care continuity; home care reduces hospital costs, but increases financial expenses for the family, which can cause difficulties in this process ${ }^{(17)}$.

The main weaknesses found in dehospitalization are the lack of planning for hospital discharge, the physician-centered model, the lack of unanimity regarding the dehospitalization criteria among the physicians and between the physicians and the other professionals. And also the challenges of preparing the user for hospital discharge and the incipient training process of caregivers and family members ${ }^{(18)}$.

With regard to the lack of planning for hospital discharge, the preparation of the caregiver while still in the hospital is listed as a strategy, when possible, by the hospital and primary health care teams, unifying practices and care transfer ${ }^{(5)}$.

The multidisciplinary team needs to work together with the family and the TDC to reduce communication noise and failures, favor knowledge exchange, and enable the development of autonomy for the child's care. For this, interaction, bonding, counseling and, above all, support to the family member must be developed, in order to succeed in the health education process for hospital discharge ${ }^{(13)}$.

In addition to that, after discharge, multiprofessional care follow-up is important, due to the clinical frailty and to the complexity of the diagnosis of the TDC ${ }^{(12)}$. Multiprofessional care for TDC is fundamental, as they require special attention related to the technology. There is a need for different perspectives, which need to be frequent and continuous, with a focus on family empowerment through education in health ${ }^{(5)}$.

In educational processes, in order to instruct family members about the home care provided to TDC, communication is the basis for promoting adequate understanding. It is necessary that the health professionals involved in care transition invest in health education to prepare the family. It is essential that all the information about the disease, procedures, tests and therapy is clearly communicated, so that the parents are able to provide care continuity ${ }^{(18)}$.
It is also important to implement a consistent hospital discharge process, which involves interdisciplinary and coordinated work to ensure integrated and articulated participation between professionals and family members and comprehensive care. In addition to that, the flows across the health services must be properly constituted ${ }^{(18)}$.

Provide care continuity at home, in addition to the family feeling prepared to meet the TDC needs at the time of hospital discharge, it is necessary to strengthen the bonds with the Primary Care (PC) team and to rely on the support of the SAD. This is considered a complementary service, responsible for working in a multidisciplinary team in an integrated manner with the Health Care Network ${ }^{(10-11)}$.

The SAD's duties are to guide and train the caregivers in a clear and objective manner, with accessible language, so as to involve them in the care process, allowing them to clarify doubts and to expose their limitations and their potentialities. It also organizes the flows for death certificates and for the admission and discharge of users in home care, in addition to promoting permanent education actions ${ }^{(10-11)}$.

With regard to the need to implement institutional protocols, a study shows that the care practice also requires exercising creativity. As they are children with unusual diseases, there is often no protocol to be used as a guide, which requires the multidisciplinary team to develop a therapeutic project focused on the singularity of each TDC. Thus, this project demands from the team the ability for innovation in the therapy, based on the affective investment in their work ${ }^{(19)}$.

Thus, it is highlighted that the accountability of only one professional to conduct the dehospitalization process and contact with the Health Care Network for the welcoming of the TDC and their families at their homes is unfeasible, as it does not follow the precepts of interprofessional work. Therefore, each professional in their specialty needs to carry out care transition, allowing for comprehensiveness, covering the biopsychosocial aspects of the child and of the family. When well executed, multiprofessional work overlaps, allowing all team members to participate in dehospitalization ${ }^{(18)}$.

However, for safe dehospitalization, qualification of the care process is necessary, which ranges from the proper filling out of records and performance of procedures, administration of medications, to investment in professional training, in addition to the involvement of the family as a co-participant in the care process ${ }^{(20)}$. The importance is reinforced of sensitizing the multiprofessional team as to the assumptions of patient safety, in particular, the safety culture.

Given the care complexity for this population, it is recommended that the multiprofessional team recognizes that care must be centered on the family, which is an essential source of support to meet the daily care needs of the TDC (4). Thus, it is necessary to articulate the health policies and 
services with the needs of this population, in order to ensure access and care continuity ${ }^{(6)}$, as well to facilitate access to health care and for the quality of life of these TDC and their families, the development of goals, programs and policies aimed at this population ${ }^{(9)}$.

\section{FINAL CONSIDERATIONS}

The study made it possible to know how dehospitalization ofTDC occurs from the perspective of the multiprofessional health team, emphasizing that this process is fragile and needs greater structuring to achieve safe hospital discharge for the children.

Although the professionals agree on the importance of dehospitalization, which allows the children to resume the routine with their family, this process occurs in a fragmented and hasty manner. This favors the provision of specific guidelines, close to hospital discharge, favoring the physician-centered health model, professional overload and communication problems. These factors preclude prior planning with the health care network and the construction of the family support network.

To improve dehospitalization, the professionals highlighted the need for a committed and cohesive team, with the objective of qualifying the post-hospital care of the children and their families, through institutional protocols aimed at organizing a safe practice.

From these results, contributions can be seen, such as improvements in the professionals' performance for the dehospitalization of TDC. Knowing this process allows these professionals to reflect on their conduct and to re-elaborate new care possibilities with a view to comprehensiveness and humanization towards TDC and their families, and also among the multidisciplinary health team members. In addition to that, it may promote a reflection on the need to organize institutional protocols that refer to care in safe dehospitalization, in order to collaborate with the integration of the health team's work.

This study made it possible to expand the production of knowledge on this topic, given that it is still a gap, as it is little explored in the care of TDC and their families, with the need for new studies. The participation of health professionals who had little time working in the service is considered as a limitation, despite the mean of 5.26 years, and that eight of the fifteen participants were working in a medical or multiprofessional residency.

\section{REFERENCES}

1. Breneol S, Belliveau J, Cassidy C, Curran JA. Strategies to support transitions from hospital to home for children with medical complexity: a scoping review. Int J Nurs Stud. 2017;72:91-104. doi: https://doi.org/10.1016/j.jjnurstu.2017.04.011
2. McPherson M, Arango P, Fox H, Lauver C, McManus M, NewacheckPW, etal. A new definition of children with special health care needs. Pediatrics. 1998;102(1):13740. doi: https://doi.org/10.1542/peds.102.1.137

3. Arrué AM, Neves ET, Magnago TSBS, Cabral IE, Gama SGN, Hökerberg YHM. Tradução e adaptação do Children with Special Health Care Needs Screener para português do Brasil. Cad Saude Publica. 2016;32(6):e00130215. doi: https://doi. org/10.1590/0102-311X00130215

4. Dias BC, Marcon SS, Reis P, Lino IGT, Okido ACC, Ichisato SMT, et al. Family dynamics and social network of families of children with special needs for complex/ continuous cares. Rev Gaúcha Enferm. 2020;41:e20190178. doi: https://doi. org/10.1590/1983-1447.2020.20190178

5. Rossetto V, Toso BRGO, Rodrigues RM, Viera CS, Neves ET. Development care for children with special health needs in home care at Paraná - Brazil. Esc Anna Nery. 2019;23(1):e20180067. doi: http://doi.org/10.1590/2177-9465-ean-2018-0067

6. Góes FGB, Cabral IE. Discourses on discharge care for children with special healthcare needs. Rev Bras Enferm. 2017;70(1):163-71. doi: https://doi. org/10.1590/0034-7167-2016-0248

7. Shapiro MC, Henderson CM, Hutton N, Boss RD. Defining pediatric chronic critical illness for clinical care, research, and policy. Hosp Pediatr. 2017;7(4):236-44. doi: https://doi.org/10.1542/hpeds.2016-0107

8. Nóbrega VM, Silva MEA, Fernandes LTB, Viera CS, Reichert APS, Collet N. Chronic disease in childhood and adolescence: continuity of care in the health care network. Rev Esc Enferm USP. 2017;51:e03226. doi: http://doi.org/10.1590/ S1980-220X2016042503226

9. Castro BSM, Moreira MCN. (Re)conhecendo suas casas: narrativas sobre a desospitalização de crianças com doenças de longa duração. Physis. 2018;28(3):e280322. doi: https://doi.org/10.1590/s0103-73312018280322

10. Ministério da Saúde (BR), Secretaria de Atenção à Saúde, Departamento de Atenção Básica. Caderno de atenção domiciliar. Ministério da Saúde. Brasília (DF): Ministério da Saúde; 2013 [cited 2020 Nov 26] Cadernos de Atenção Básica, v. 2. Available from: https://bvsms.saude.gov.br/bvs/publicacoes/caderno_atenca_ domiciliar_melhor_casa.pdf

11. Ministério da Saúde (BR). Portaria nº 825, de 25 de abril de 2016. Redefine a Atenção Domiciliar no âmbito do Sistema Único de Saúde (SUS) e atualiza as equipes habilitadas. Diário Oficial da União. 2016 abr 25 [cited 2020 Nov 26];153(78 Seção 1):33-8. Available from: https://pesquisa.in.gov.br/imprensa/jsp/visualiza/ index.jsp? data $=26 / 04 / 2016 \&$ jornal=1\&pagina $=33 \&$ totalArquivos $=112$

12. Brenner M, Kidston C, Hilliard C, Coyne I, Eustace-Cook J, Doyle C, et al. Children's complex care needs: a systematic concept analysis of multidisciplinary language. Eur J Pediatr. 2018;177:1641-52. doi: https://doi.org/10.1007/s00431-018-3216-9

13. Silveira A, Alves BTG, Elauterio MP, Silva FO, Costa SY, Souza NS. Participação e ausência familiar: implicações para o desenvolvimento de crianças e adolescentes com necessidades especiais. Rev Contexto Saúde. 2020;20(38):185-90. doi: http:// doi.org/10.21527/2176-7114.2020.38.185-190

14. Cruz CT, Zamberlan KC, Silveira A, Buboltz FL, Silva JH, Neves ET. Care to children requiring continuous and complex assistance: nursing perception. REME. 2017;21:e1005. doi: http://doi.org/10.5935/1415-2762.20170015

15. Ribeiro J, Souza FN, Lobão C. Saturação da análise na investigação qualitativa: quando parar de recolher dados? [editorial]. Rev Pesqui Qual. 2018;6(10):iii-vii. doi: https://doi.org/10.33361/RPQ.v.6.n.10

16. Minayo MCS, Deslandes SF, Gomes R, organizadores. Pesquisa social: teoria, método e criatividade. Petrópolis: Vozes; 2016.

17. Dias BC, Arruda G0, Marcon SS. Family vulnerability of children with special needs of multiple, complex and continuous care. REME. 2017;21:e-1027. doi: http:// www.doi.org/10.5935/1415-2762.20170037 
18. Silva-Rodrigues FM, Bernardo CSG, Alvarenga WA, Janzen DC, Nascimento LC. Transitional care to home in the perspective of parents of children with leukemia. Rev Gaúcha Enferm. 2019;40:e20180238. doi: https://doi. org/10.1590/1983-1447.2019.20180238

19. Azevedo CS, Pfeil NV. No fio da navalha: a dimensão intersubjetiva do cuidado aos bebês com condições crônicas complexas. Physis. 2019;29(4):e290406. doi: https://doi.org/10.1590/s0103-73312019290406

\section{- Authorship contribution:}

Kassiely Klein: Conceptualization, data curation, formal analysis, investigation, methodology, project management, resources, visualization, writing - original draft preparation, and writing - review and editing. Helena Becker Issi: Conceptualization, formal analysis, investigation, methodology, project management, resources, supervision, visualization, writing - original draft preparation, and writing - review and editing. Neila Santini de Souza: Methodology, project management, resources, supervision, visualization, writing - original draft preparation, and writing review and editing.

Aline Cammarano Ribeiro: Methodology, project management, resources, supervision, visualization, writing - original draft preparation, and writing review and editing.

Érika Eberlline Pacheco dos Santos: Writing - original draft preparation, and writing - review and editing. Graciela Dutra Senhem: Writing - original draft preparation, and writing - review and editing.

The authors declare no conflict of interests.

\section{- Corresponding author:}

Aline Cammarano Ribeiro

E-mail: aline.cammarano-ribeiro@ufsm.br
20. Wegner W, Silva MUM, Peres MA, Bandeira LE, Frantz E, Botene DZA, et al. Patient safety in the care of hospitalised children: evidence for paediatric nursing. Rev Gaúcha Enferm. 2017;38(1):e68020. doi: https://doi. org/10.1590/1983-1447.2017.01.68020

Associate editor:

Wiliam Wegner

Editor-in-chief:

Accepted: 01.21.2021

Maria da Graça Oliveira Crossetti 